\title{
Using African American Perspectives to Promote a More Inclusive Understanding of Human Communication Theory ${ }^{1}$
}

\author{
Jim Schnell \\ Ohio Dominican College
}

\begin{abstract}
This article addresses the use of African American Perspectives as a means of promoting a more inclusive understanding of human communication theory. It describes contributions by African American scholars as they relate to providing a framework for inclusion of other under-represented cultures in U.S. society (i.e. Asian American, Latin American, etc.). This objective is becoming more and more relevant because of the increased percentage of U.S. citizens who are of non-European origin. Common sense supports the position that an inclusive curriculum, representative of the many cultural groups that compose the U.S., will appeal to the diverse audience educated in the U.S. today and tomorrow.
\end{abstract}

The education curriculum is never finished. It is dynamic and continually in a state of change. This article focuses on the use of research findings by African American scholars that expands the communication arts curriculum as a means of re-shaping the curriculum so it is more representative of the various cultures that compose U.S. society. This move towards a more multicultural curriculum should encourage eventual focus on all U.S. cultural backgrounds. This article addresses contributions by African American scholars, which are not presented here as a single Afrocentric perspective, and is intended to provide a framework for inclusion of other under represented cultures in the U.S. (i.e. Asian American, Latin American, etc.).

Within five years, roughly $33 \%$ of school age children in the U.S. will be of non-European origin. ${ }^{2}$ Thus, we have a unique opportunity and obligation to ensure our academic curricula are representative of 
these non-European perspectives. Thorough modifications will be a lengthy process. Calls for a more inclusive curriculum representative of the multicultural composition of American society have come from a variety of sources. ${ }^{3}$ One frequently hears that we need emphasis on education as a means to help American society get along with itself (in the area of inter-racial/ethnic relations).

The aforementioned inclusive curriculum can obviously be attained only when scholarship representative of all American cultures is included in curriculum expansion efforts. Emphasis on the research of African American scholars within this article is intended as one of the many steps towards an inclusive curriculum. And, obviously, communication arts is but one of the many disciplines to be expanded.

A review of literature on the subject of curriculum development and multicultural inclusiveness reveals little that deals with models for curricular development specifically in communication arts. However, much has been written on curriculum development and multicultural inclusiveness that can be applied in communication arts and other disciplines within the social sciences. Helle Bering-Jensen ${ }^{4}$ recommends inclusion of minority contributions in classroom content as a means of supplementing Eurocentric perspectives. Beverly Tatum ${ }^{5}$ offers strategies for overcoming student resistance to race-related content. Emphasis on inclusion of culturally diverse works of literature is described in Pforderesher ${ }^{6}$ and Post. ${ }^{7}$ Michael Harris ${ }^{8}$ suggests addressing racial problems through inclusion of African and African American content. Kerry Feldma ${ }^{9}$ shows how anthropology departments can be helpful in choosing multicultural education components. Jerry Gaff ${ }^{10}$ claims that multiculturalism has won the war against Euorcentrism and that we should move to the next step of creating inclusive programs that are educationally valuable. These views point to the need for expansion of the curriculum. Again, the focus of this article is on the inclusion of African American scholarship as an initial objective, with the inclusion of scholarship representative of all American cultures being the primary, longterm objective.

During the past quarter century many colleges and universities have tried to include minorities in their curriculums through the creation of African American Studies departments that stress black contributions. It is a central premise of the Lilly Foundation grant proposal, that funded the research undertaken by this author, that "if majority students are to gain the benefits of the minority perspectives, we believe that the contributions of minorities should claim their proper place throughout the curriculum and not be relegated to a 'separate but distinct' area."11

This author has approached the research of African American scholarship as an opportunity to substantively augment his academic orientation. One could merely use a recipe approach of "just add African American readings and stir" but this would only allow for cosmetic 
changes. Rather, this author has approached this as he did his graduate school years. Knowledge learned is intended to become part of his theoretical fabric. Such an approach takes time and thorough analysis. His graduate training was a long in depth period of study. Any serious modifications of that foundation will come through a similar path.

The communication arts discipline covers a wide range of subject areas including public speaking, interpersonal communication, organizational communication, mass media, rhetoric, journalism, public relations, broadcasting, theater, and cross-cultural studies. The author has focused on five courses he teaches: Rhetorical Communication Theory, Mass Media in America, Persuasion, Communication in the Organization, and a Unity in Diversity course. A majority of the works are most appropriate in the Unity in Diversity course. Examples of course modifications will be described to exemplify how curricular change in communication arts can be perpetuated.

Before addressing specific course modifications, it will be helpful to describe the process through which this author gathered contributions of African American scholars. Essential in this process were visits to the Moorland-Spingarn Research Center at Howard University. It is the "largest and the most valuable research library in America for the study of Negro life and history" and "the most comprehensive and interesting group of books by Negroes ever collected in the world." ${ }^{12}$ Such a comprehensive collection of African American scholarship offers a unique opportunity to study African American contributions in a variety of areas.

The author used a variety of key words to search for information relevant to communication arts. The seven most useful key words were rhetoric, communication, narration, persuasion, political oratory, nonverbal communication, and interpersonal relations. The following lists, in parentheses, the number of relevant titles found under each key word heading: rhetoric (36), communication (75), narration (71), persuasion (6), political oratory (7), nonverbal communication (17), and interpersonal relations (35).

Rhetorical Communication Theory is an upper-level course at Ohio Dominican College. The course traces the development of rhetoric from the classical period, to the British period, to the contemporary period. Two primary assignments in the course are a research paper on a significant rhetorician and an oral presentation in class about the research. The suggested list of rhetoricians includes individuals representing a variety of perspectives. No African Americans were included in the list. As a result, the following African American names have been added to the list as possible rhetoricians to be studied: W.E. B. DuBois, Sterling Brown, Ralph Ellison, and Toni Morrison. Thus, the list is more inclusive of African American perspectives. Students are also encouraged to suggest other African American rhetoricians for study.

Students choosing to study the African American rhetoricians 
might use, as a foundation for their research, works such as The Anatomy of Black Rhetoric, ${ }^{13}$ A Comparative Study of Two Approaches for Analyzing Black Discourse, ${ }^{14}$ Rhetoric of Racial Hope, ${ }^{15}$ The Relationship Between Errors in Standard Usage in Written Compositions of College Students and the Students' Cognitive Styles ${ }^{16}$ From Behind the Veil: $A$ Study of African-American Narrative, ${ }^{17}$ and Black Communication. ${ }^{18}$ These works, authored by African American writers, focus on African American rhetoric. Again, no single Afrocentric perspective is promoted in this approach.

The Mass Media in America course uses a textbook entitled Introduction to Mass Media. ${ }^{19}$ It can be supplemented with Split Image ${ }^{20}$ and Mass Media in America. ${ }^{21}$ These works better highlight the role of African Americans in mass media. Other sources regarding the role of African Americans are found in an extensive bibliography entitled "Blacks in the Media: Communication Research Since 1978,"22 published by the Howard University Center for Communication Research.

The Persuasion course describes persuasion theory and contemporary applications of persuasion theory. One of these applications involves persuasion in public speaking. Contemporary public speakers can be used for case study analysis in the course. This is an excellent opportunity to promote inclusion of African Americans (i.e. the Jesse Jackson address at the 1988 Democratic National Convention, the Martin Luther King, Jr. "I Have a Dream" speech, etc.).

The Communication in the Organization course emphasizes communication in interpersonal, group, and organizational settings. African American scholarship can easily be included to enhance understanding of communication processes in these contexts. It is suggested that one simple guideline for text selection in such a course is to analyze possible textbooks regarding the extent of multi-cultural inclusion in case studies, examples, photographs and overall content. This guideline would obviously be beneficial when considering textbooks for other courses in the communication arts curriculum as well.

The Unity in Diversity course is a new course that was developed under the auspices of the aforementioned Lilly Grant. This course is team taught by Judith Abala (a black female) and Jim Schnell (a white male). This course, developed by Abala and Schnell, is an introductory course that explores the implications of belonging to a culturally pluralistic society with all of its richness, complexities, challenges and responsibilities. The course seeks to enhance the ability of students to interact with culturally different individuals who comprise American society. There is no textbook for the course. Instead, a readings booklet allowing comprised of many types of articles has been compiled.

There are a variety of sources by black authors relevant for study in the Unity in Diversity course. Such references include Handbook of Intercultural Communication ${ }^{23}$ and African American Communications. ${ }^{24}$ 
These works offer perspectives on the complexities of communication among American cultures and can be helpful in enhancing student understanding. Unity in Diversity is an experimental course at the time of this writing. It has the potential for being added to the core requirement courses.

A common objective in all of these courses, regarding inclusion of African American perspectives, is to empower students to discover African American contributions and share their discoveries in class. This allows for the individual student to learn, his/her fellow classmates to learn, and the professor to learn. This empowerment is preferable to an approach that is driven solely by the faculty member. To empower the student to learn the process for discovering African American contributions allows for more self-initiated learning by the student.

Future curricular development will benefit from increased inclusion of other cultural perspectives. These perspectives obviously exist in the communication arts curriculum but, perhaps, not to the degree that they should. We should aim to increase inclusion of all cultural perspectives. The modification process described in this article is offered as a model for future development regarding the creation of a multicultural curriculum.

\section{NOTES}

${ }^{1}$ Special thanks is extended to Jannette Dates (Dean, School of Communication, Howard University) for her hospitality and support during my visits to Howard University. I am also grateful to Bill Carroll (President, Illinois Benedictine College) for his support. Funding for the program described in the report was obtained through a grant from the Lilly Foundation.

${ }^{2}$ Channing L. Bete, Learn About Diversity. (South Deerfield, MA: 1993), 4.

${ }^{3}$ Michael A. Williams, Blacks and the Media: Communication Research Since 1978. (Washington, DC: Howard University, 1990); Dibra Viadero, "Issue of Multiculturalism Dominates Standards Debate," Education Week 11, 31 (April 22, 1992), 18; Edmund W. Gordon and Maitrayee Bhattacharyya, "Human Diversity, Cultural Hegemony, and the Integrity of the Academic Canon," Journal of Negro Education 61, 3 (Summer, 1992), 405-418.

${ }^{4}$ Helle Bering-Jensen, "Teaching All Things to All People," Insight 6,14 (April 2, 1990), 49-51. 
${ }^{5}$ Beverly Daniel Tatum, "Talking About Race, Learning About Racism: The Application of Racial Identity Development Theory in the Classroom," Harvard Educational Review 62, 1 (February, 1992), 1-24.

6John Pfordresher, "Better and Different Literature in Our Time," Design for Arts in Education 93, 4 (March, 1992), 2-10.

${ }^{7}$ David Post, "Through Joshua Gap: Curricular Control and the Constructed Community," Teachers College Record 93, 4 (Summer, 1992), 673-696.

${ }^{8}$ Michael D. Harris, Afrocentrism and Curriculum: Concepts, Issues, and Prospects," Journal of Negro Education 61, 3 (Summer, 1992), 301 316.

${ }^{9}$ Kerry D. Feldman, "Multicultural Education and Antrhropology: 'The Rise of Civilization' as a Foundation Course," Human Organization 51, 2 (Summer, 1992), 185-186.

${ }^{10}$ Jerry G. Gaff, "Beyond Politics," Change 24,1 (January, 1992), 30-35.

"Ohio Dominican College, "Improving Multicultural Climate at a FourYear College," (1991). A grant proposal funded by the Lilly Foundation.

${ }^{12}$ The Arthur B. Spingarn Collection of Negro Authors. (Washington, DC: Moorland Foundation, Howard University Library, n.d., 1947), 1 and 7.

${ }^{13}$ James C. Payne, The Anatomy of Black Rhetoric. (Tallahassee, FL: Graphic Communications Associates, 1972).

${ }^{14}$ Leon C. Phillips, A Comparative Study of Two Approaches for Analyzing Black Discourse. (Dissertation: Howard University, 1983).

${ }^{15}$ Roy L. Hill, Rhetoric of Racial Hope. (Brockport, NY: McDaniel Press, 1976).

${ }^{16}$ Grace C. Cooper, The Relationship Between Errors in Standard Usage in Written Compositions of College Students and the Students Cognitive Styles. (Dissertation: Howard University, 1979).

${ }^{17}$ Robert B. Stepto, From Behind the Veil: A Study of African-American Narrative. (Chicago: University of Illinois Press, 1979).

${ }^{18}$ Robert Mullen, Black Communication. (Lanham, MD: Universeity Press of America, 1982). 
${ }^{19}$ Jay Black and Jennings Bryant, Introduction to Mass Media. (Dubuque, IA: Wm. C. Brown, 1992).

20Jannette Dates and William Barlow, Split Image; African Americans in the Mass Media. (Washington, DC: Howard University Press, 1990).

${ }^{21}$ Donald Pember, Mass Media in America. (New York: Macmillan Publishing, 1992).

${ }^{22}$ Michael A. Williams, Blacks and the Media: Communication Research Since 1978. (Washington, DC: Howard University, 1990).

${ }^{23}$ Molefi Kete Asante, Eileen Newmark and Cecil Blake, Handbook of Intercultural Communication. (Beverly Hills, CA: Sage Publishers, 1979).

${ }^{24} \mathrm{James}$, Ward, African American Communications: An Anthology In Traditional and Contemporary Studies. (Dubuque, IA: Kendall/Hunt Publishing, 1991). 